\title{
THE MAIN FACTORS AFFECTING THE ACCURACY DURING THE MANUFACTURING PROCESS BASED ON MATERIAL EXTRUSION
}

\author{
Daniel Besnea ${ }^{1}$, Alina Spanu ${ }^{2}$, Victor Constantin ${ }^{3}$, \\ 1,2,3University POLITEHNICA of Bucharest, Faculty of Mechanical Engineering and Mechatronics, \\ Department Mechatronics and Precision Mechanics

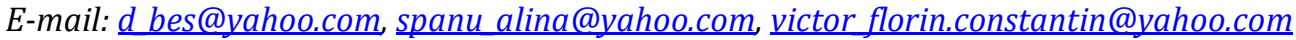

\begin{abstract}
The paper presents the study in manufacturing accuracy regarding the factors that are affecting the processes based on material extrusion, such as: FDM (fused deposition modeling) and additive technologies for melted plastics. In order to do this, the three dimensional model with complex shapes should to be made, so that the manufacturing process on 3D printers may start. The analysis comprises the using of three 3D printers types all of them working with four different materials characterized by distinctive technical properties, whose diameter is $1.75 \mathrm{~mm}$.
\end{abstract}

Keywords: Material Extrusion, 3D Printing, Manufacturing Accuracy.

\section{Introduction}

The processes based on material extrusion use a thread made of distinctive materials that is warming nearby the melting temperature at first. After that its diameter is reduce by extrusion at $0.2 \mathrm{~mm}$ into a deposition device moving inside the XOY plane, so the layer of the virtual model will be manufactured. The entire process is based on the material warming, nearby its melting point. The second stage will be the deposition on the layer for manufacturing the part.

The process has three main stages: the first one is the preprocessing; the second one is the manufacturing, having the most important role and finally the post processing. During the first stage, the three dimensional CAD model has to be uploaded by using the software Quick Slice, which is specific for the FDM device. After that, we have to do the spatial Part positioning, so that the manufacturing time and the material resources would be optimized. This activity is done with special functions such as rotation, translation and mirror. Once the Part was positioned, the cutting with parallel plans meantime parallel with the 3D printer working plan will be done. As a result, many intersection curves will be delimited and they are named boarders. Along the $\mathrm{Z}$ axis we may define the cutting step whose value depends on material properties and on the nozzle diameter value, both of them for PLA for instance. During the experimental setup, we have worked with $0.4 \mathrm{~mm}$ for nozzle diameter.

Finally, the level curves will result, then a global analysis will be done with Quick Slice software in order to provide the support surface for each particular Part structure. When all the trajectories that the extruder should follow are computed, the last activity of the pre-processed stage is the information saving in a new command file.

The stage of Part manufacturing as a main activity has the following activities:

- The warming - extruder head of the printer makes the deposition of a very thin thread made of PLA following the curves, which define the surface boundaries.

- The material deposition in the areas where the Part thickness is bigger;

- If it is necessary, the support layer will be manufactured too and later it will be cut;

- After the entire layer has been manufactured the printer platform will move down to the next step of the virtual model.

- For a new section manufacturing the cycle will be reload.

The manufacturing stage of the Part will be closed after the last section of the virtual model.

The last after - processing stage comprises:

- The Part separation from the manufacturing platform

- The removing of the support layer

- The Part finishing $[1,2]$.

\section{Technical Description}

Since the design process, we have to take into account the manufacturing time shortening that is influenced by the Part orientation in order to avoid the grounded layer generation. Consequently, the minimum dimension will be along the $\mathrm{Z}$ axis and the step value will be established by Quick Slice software (Fig. 5).

The manufacturing time could be influenced by the Part complexity because of the material support bigger quantity due the complex Part shapes. 
Starting with the design stage, we have aimed to include all the surface types, such as concave, convex, plane, concentric, cavities to point out the manufacturing accuracy that characterizes some 3D printers we have worked with using some materials. In Table 1 there are described the materials we have used for Part manufacturing and their technical properties. [1, 2]

The CAD model by its complex shapes points out the step effect, because there are some inclined surfaces following small angles measured from the horizontal plane, as well as spherical, concave, convex and coaxial shapes. [3].

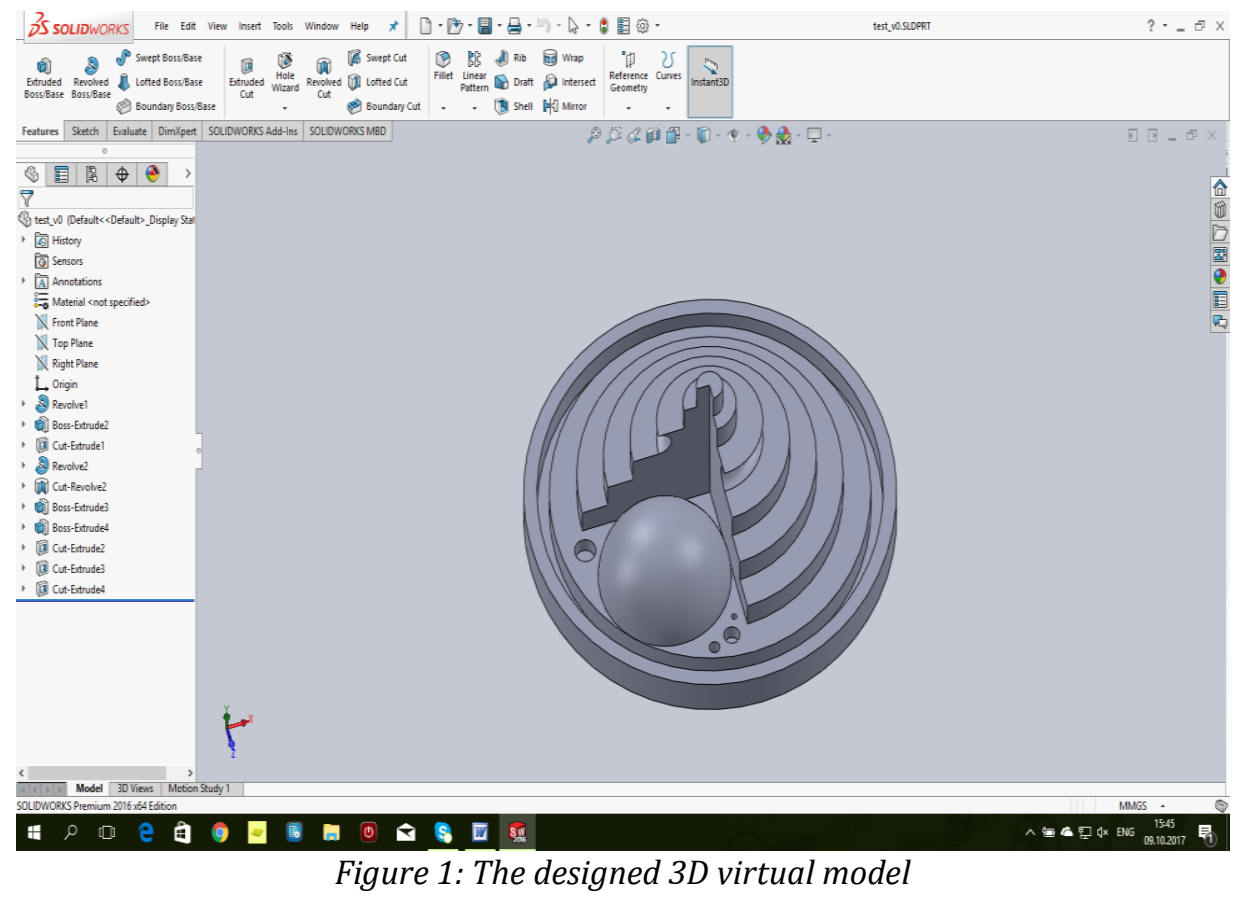

In order to emphasize the main elements of the virtual model, the following references from the nominal dimensions will be taken into account for the Part $[3,4]$.

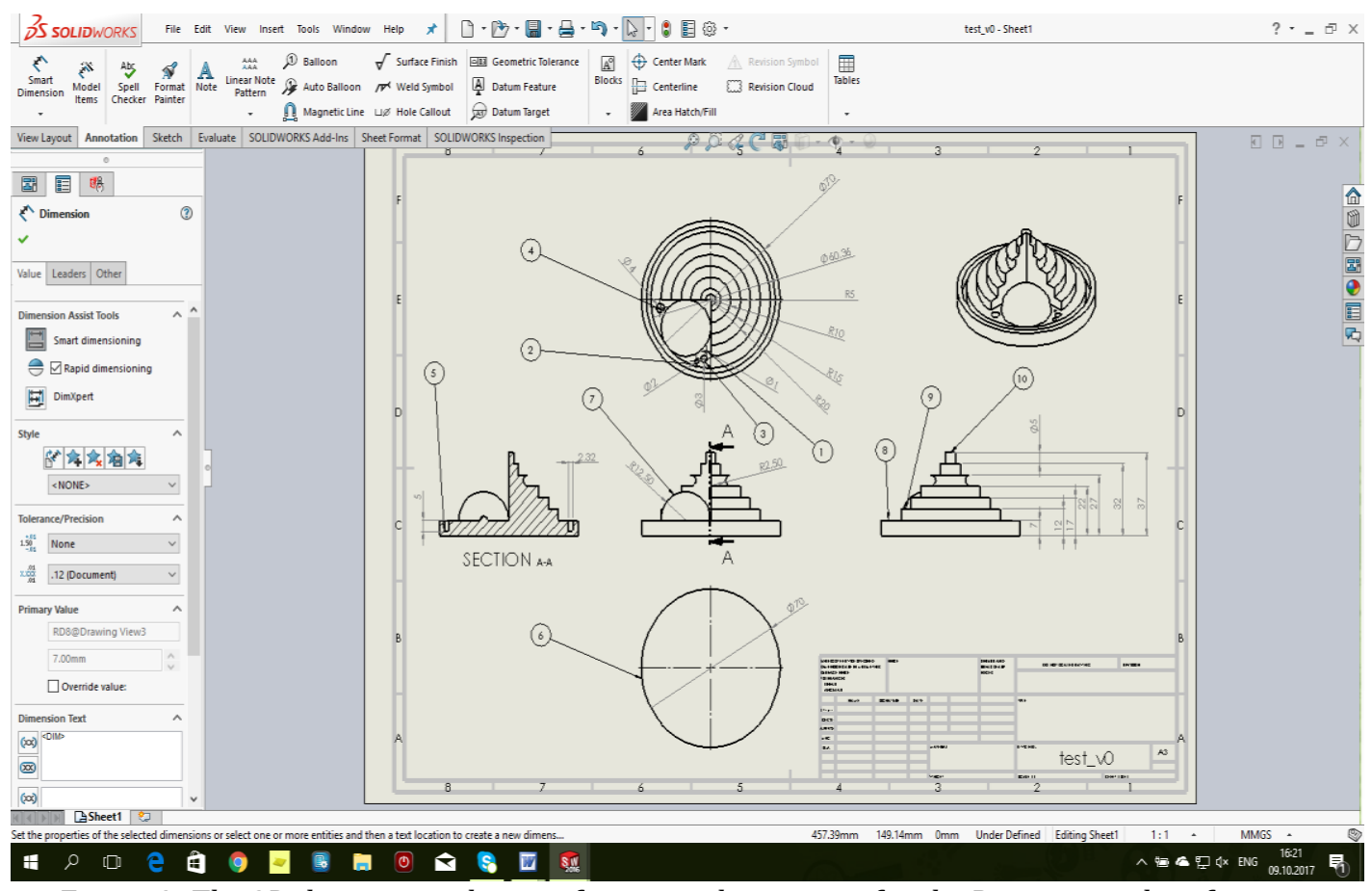

Figure 2: The 2D drawing with manufacturing dimensions for the Part test and surface test

On the Part test surface we may identify ten main surface types that are presented in Table 1, which could be measured with specific devices found in the Prototype Laboratory. 
Table 1

\begin{tabular}{|c|c|c|}
\hline No. & Surface type & $\begin{array}{c}\text { Nominal drawing } \\
\text { size }\end{array}$ \\
\hline 1 & Surface 1 & $\Phi 1 \mathrm{~mm} ;$ \\
\hline 2 & Surface 2 & $\Phi 2 \mathrm{~mm}$ \\
\hline 3 & Surface 3 & $\Phi 3 \mathrm{~mm}$ \\
\hline 4 & Surface 4 & $\Phi 4 \mathrm{~mm}$ \\
\hline 5 & Surface 5 & $5 \mathrm{~mm}$ \\
\hline 6 & Surface 6 & $\Phi 70 \mathrm{~mm}$ \\
\hline 7 & Surface 7 & $12.5 \mathrm{~mm}$ \\
\hline 8 & Surface 8 & $7 \mathrm{~mm}$ \\
\hline 9 & Surface 9 & $12 \mathrm{~mm}$ \\
\hline 10 & Surface 10 & $37 \mathrm{~mm}$ \\
\hline
\end{tabular}

The basic material used for manufacturing of all Parts is PLA (polylactic) with the diameter $1.75 \mathrm{~mm}$ and $210^{\circ} \mathrm{C}$ working temperature. This material was made by some plants processing such as: corn, sugar beet, potatoes, without any dangerous element, with environment compatibility, with resistance and harder than ABS (working at $110^{\circ} \mathrm{C}$ ). It is not recommended to use it for some assemblies because of its elasticity at lower temperatures $\left(65^{\circ} \mathrm{C}\right)$ for the objects that will be manufactured in normal temperature conditions.

The technical characteristics for the four material types are presented in Table 2 .

\begin{tabular}{|c|c|c|}
\hline No. & Material & Technical specifications \\
\hline 1 & PLA WOOD, diameter $1.75 \mathrm{~mm}$ & $\begin{array}{l}\text { New material which gives an wood aspect for the } \\
\text { printed parts, is used for interior design, wood } \\
\text { models and prototypes. The thread is made of } \\
\text { composite material wood and PLA, made in USA. The } \\
\text { manufactured models are working at temperature } \\
\text { lower than } 60^{\circ} \mathrm{C} \text {. }\end{array}$ \\
\hline 2 & $\begin{array}{l}\text { PLA Temperature Change, } \\
\text { diameter } 1.75 \mathrm{~mm}\end{array}$ & $\begin{array}{l}\text { The 3D thread has the property of color changing } \\
\text { when the temperature is varying. Those threads have } \\
\text { a good surface quality; the contraction rate is lower } \\
\text { without and deformation. The manufactured models } \\
\text { are working at temperatures lower than } 60^{\circ} \mathrm{C} \text { and tey } \\
\text { are made for educational aim. }\end{array}$ \\
\hline 3 & $\begin{array}{l}\text { PLA transparent Colour, } \\
\text { diameter } 1.75 \mathrm{~mm}\end{array}$ & $\begin{array}{l}\text { The } 3 \mathrm{D} \text { thread is transparent, it has a lower melting } \\
\text { point } 190^{\circ} \mathrm{C} \text {, it is not toxic, it is used for models with } \\
\text { high resolution. }\end{array}$ \\
\hline 4 & $\begin{array}{l}\text { PLA green Colour, diameter } 1.75 \\
\mathrm{~mm}\end{array}$ & $\begin{array}{l}\text { The thread was designed for high resolution models, } \\
\text { the melting point } 190^{\circ} \mathrm{C} \text {, the printing speed is } 40- \\
100 \mathrm{~mm} / \mathrm{s} \text {. }\end{array}$ \\
\hline 5 & $\begin{array}{l}\text { PLA MakerBot, diameter } 1.75 \\
\text { mm }\end{array}$ & $\begin{array}{l}\text { The thread was designed for MakerBot Replicator, it } \\
\text { is working at } 215^{0} \mathrm{C} \text {, with high tolerance for constant } \\
\text { pouring through the nozzle. Each color is quality } \\
\text { tested for layer resolution } 100 \text { and } 200 \text { in order to } \\
\text { verify if the thread is working with the characteristics } \\
\text { given by MakerBot Replicator. }\end{array}$ \\
\hline
\end{tabular}

The virtual model was printed on three printers all of them with Fused Deposition Modeling (FDM) technology with thin layers made of melted plastic material.

\author{
Technical characteristics for 3D MakerBot \\ Replicator (Fig. 3) \\ Conectivity: USB, wireless \\ Build Volume: $252 \times 199 \times 150 \mathrm{~mm}$ \\ Filament Diameter: $1.75 \mathrm{~mm}$ \\ Diameter nozzle: $0.4 \mathrm{~mm}$; \\ Minimum Layer Height: $0.2 \mathrm{~mm}$ \\ Quality: Standard \\ Number of Heads: 1 \\ Build Speed: $30 \mathrm{~mm} / \mathrm{s}$ \\ Format files to print: STL \\ Technology: FDM [6]
}

Table 2

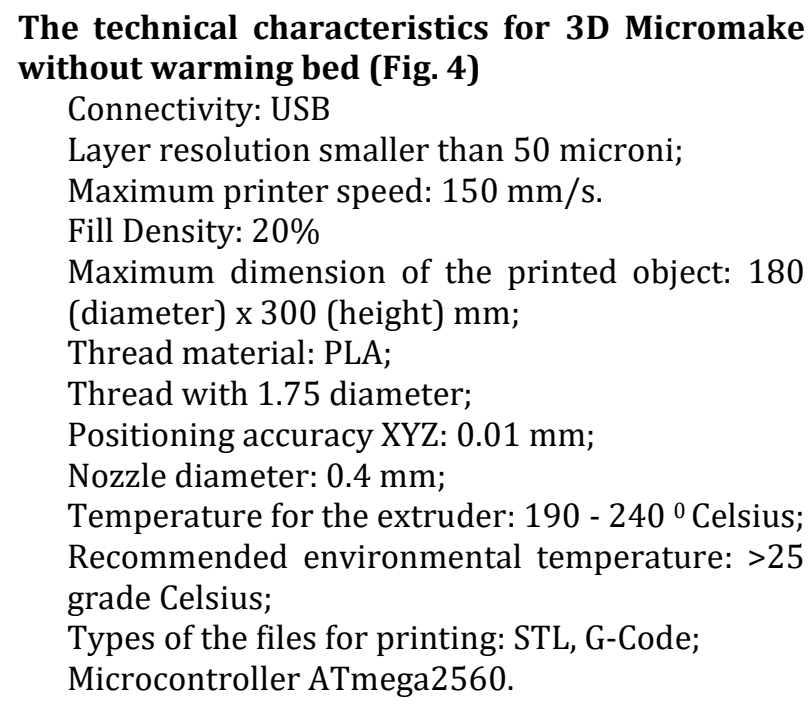




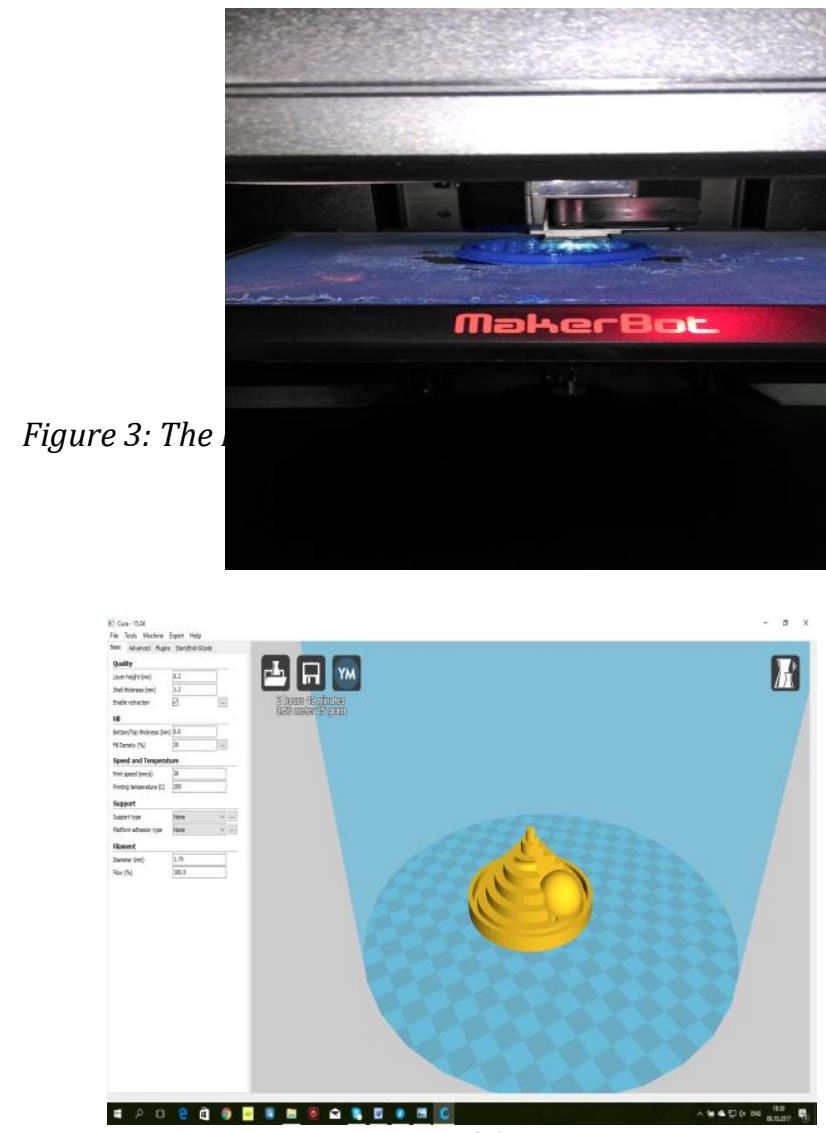

(a)

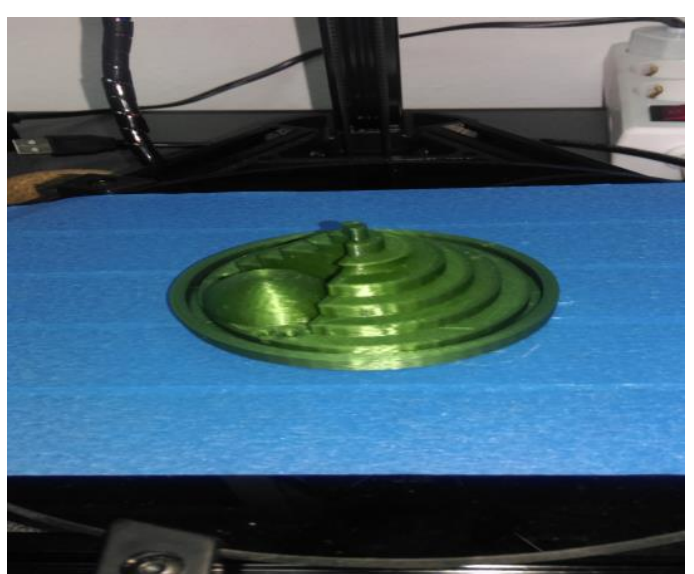

(c)
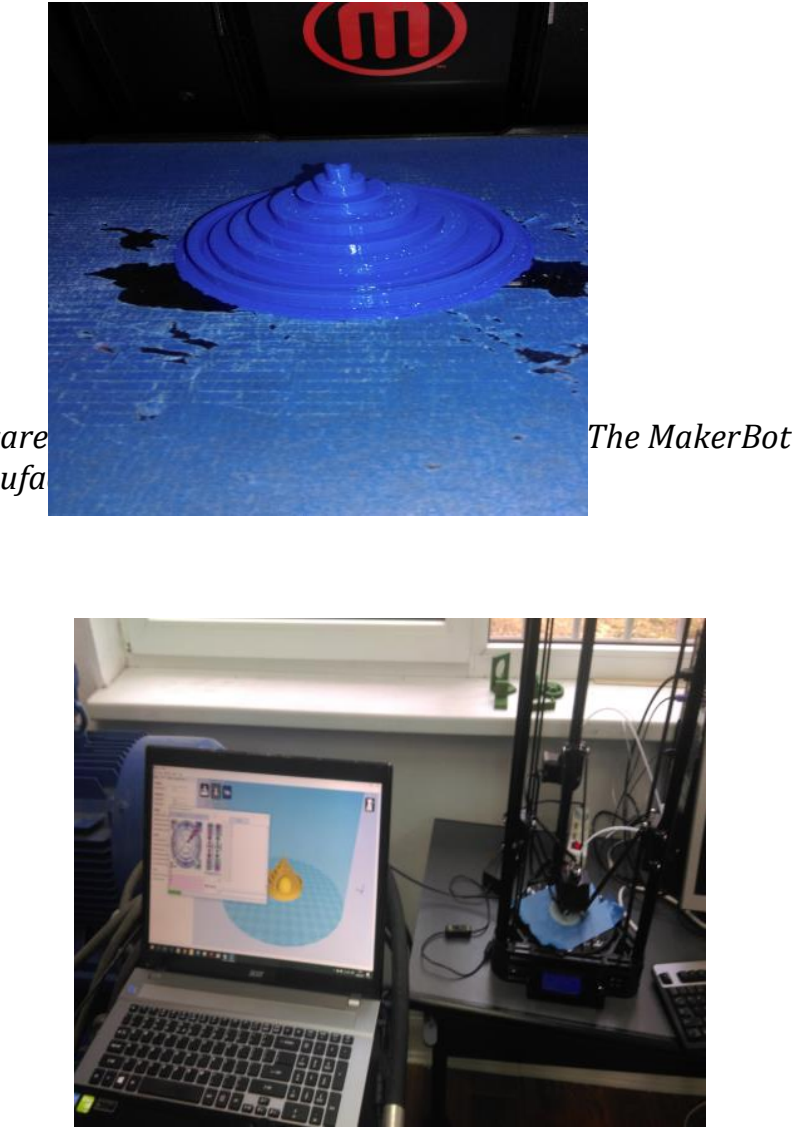

(b)

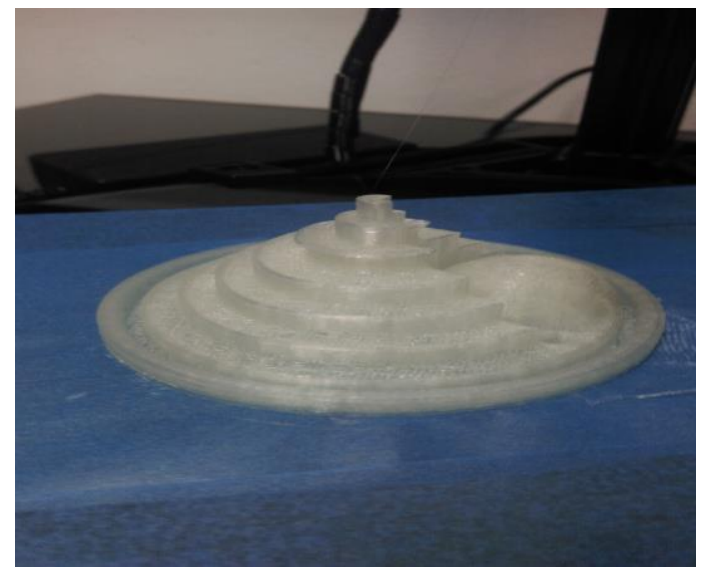

(d)

Figure 4: Micromake 3D printer: $a$ - CURA control command interface of the printer; $b$ - 3D Micromake printer; $c$-green PLA test piece; $d$-transparent PLA test piece.

Technical characteristics for 3D printer without warming bed (Fig. 5)

Connectivity: USB

Build Volume: $400 \times 400 \times 250 \mathrm{~mm}$;

Material filament: PLA;

Filament Diameter: $1.75 \mathrm{~mm}$;

Positioning accuracy XYZ: $0.01 \mathrm{~mm}$;
Diameter nozzle: $0.4 \mathrm{~mm}$;

Recommended extruder temperature: 190 $240^{\circ} \mathrm{C}$;

Recommended ambient temperature: $>25^{\circ} \mathrm{C}$;

Format files to print: STL, G-Code;

Operating system: Arduino/Repetier-Host 


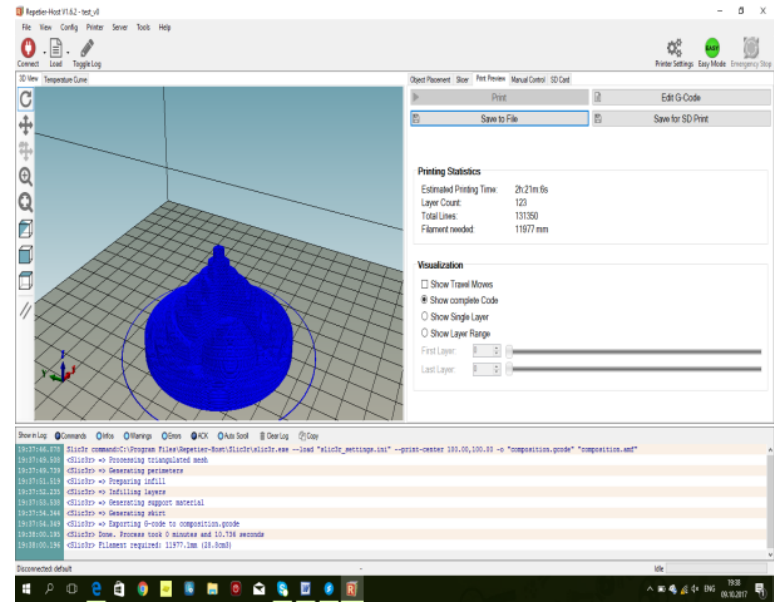

(a)

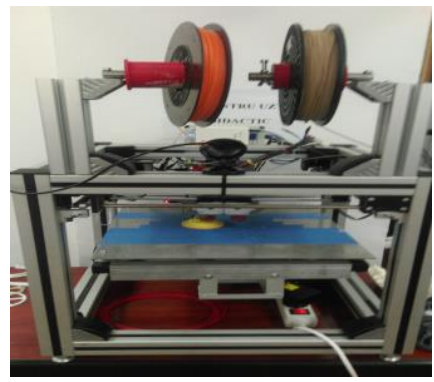

(c)

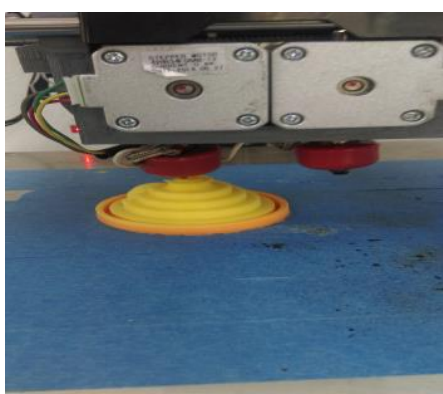

(e)

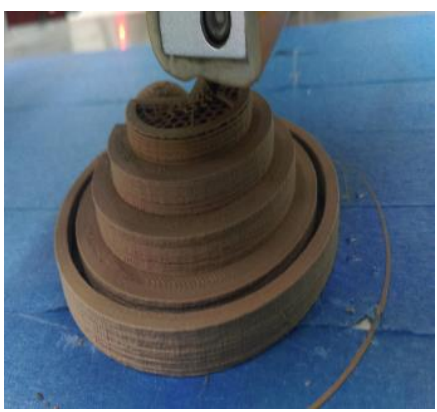

(g)

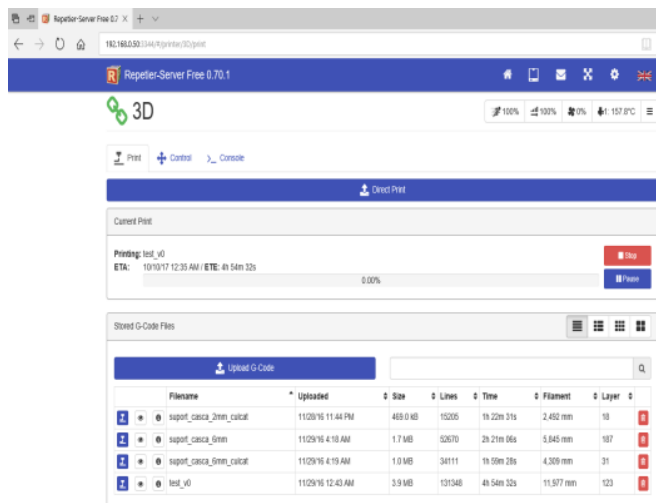

A $P$ O

(b)

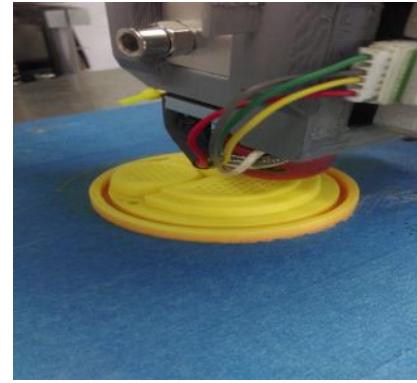

(d)

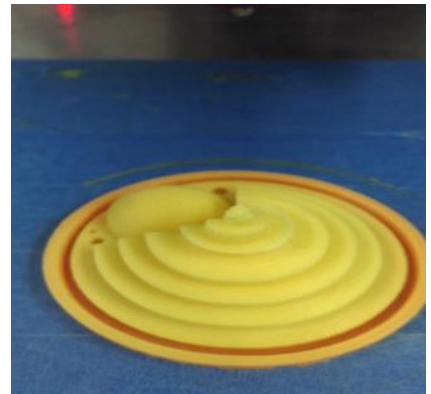

$(f)$

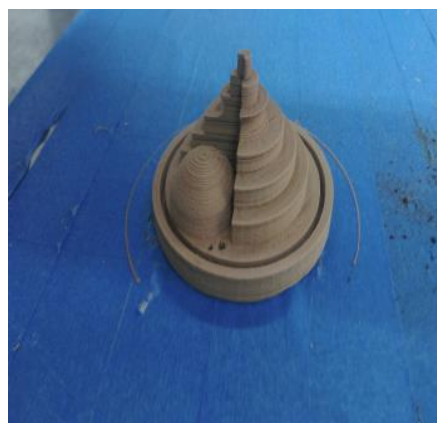

(h)

Figure 5: The 3D printer without warming bed: $a$ - the working window of software Quick Slice;

$b$ - the working window of software Repetier Host; $c$ - the working printer; $d, e$ - the test part during printing,

thermo- chromatic material; $f$ - the final Part printed of thermo- chromatic material; $g$ - the test part during printing made of composite material wood with PLA; $h$ - the final Part made of composite material wood with PLA

The surface verification for the test Part was made with the following devices: digital caliper beam, the working range values $0-150 \mathrm{~mm}$, the value of graduation is $0.01 \mathrm{~mm}$, used for shape verification 1.2.3.4.5.6.7.10 and digital micrometer the working range values $0-30 \mathrm{~mm}$, the value of graduation is $0.001 \mathrm{~mm}$ for the surface checking 8 and 9 [5]. 


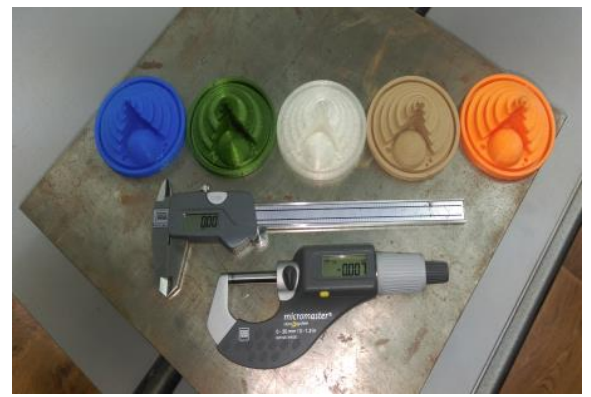

Figure 6: The dimensional checking for the test surfaces of the five parts.

The numerical values for experimental determination of the ten main surfaces are presented in table 3

\begin{tabular}{|c|c|c|c|c|c|c|}
\hline $\begin{array}{c}\text { Nominal } \\
\text { dimension }\end{array}$ & Nominal & P1 & P2 & P3 & P4 & P5 \\
\hline 1 & 1.00 & 1.04 & 0.96 & 0.82 & 0.98 & 1.02 \\
\hline 2 & 2.00 & 1.86 & 1.61 & 1.67 & 1.92 & 1.83 \\
\hline 3 & 3.00 & 2.69 & 2.43 & 2.73 & 2.75 & 2.92 \\
\hline 4 & 4.00 & 3.82 & 3.79 & 3.64 & 3.76 & 3.37 \\
\hline 5 & 5.00 & 5.44 & 4.64 & 4.23 & 5.17 & 5.21 \\
\hline 6 & 7.00 & 6.97 & 7.05 & 6.95 & 7.09 & 6.99 \\
\hline 7 & 12.50 & 12.09 & 12.08 & 12.41 & 13.38 & 12.91 \\
\hline 8 & 7.00 & 7.09 & 6.87 & 6.47 & 6.81 & 6.55 \\
\hline 9 & 12.00 & 11.94 & 11.79 & 11.64 & 12.20 & 11.71 \\
\hline 10 & 3.70 & 3.71 & 3.71 & 3.72 & 3.69 & 3.68 \\
\hline
\end{tabular}

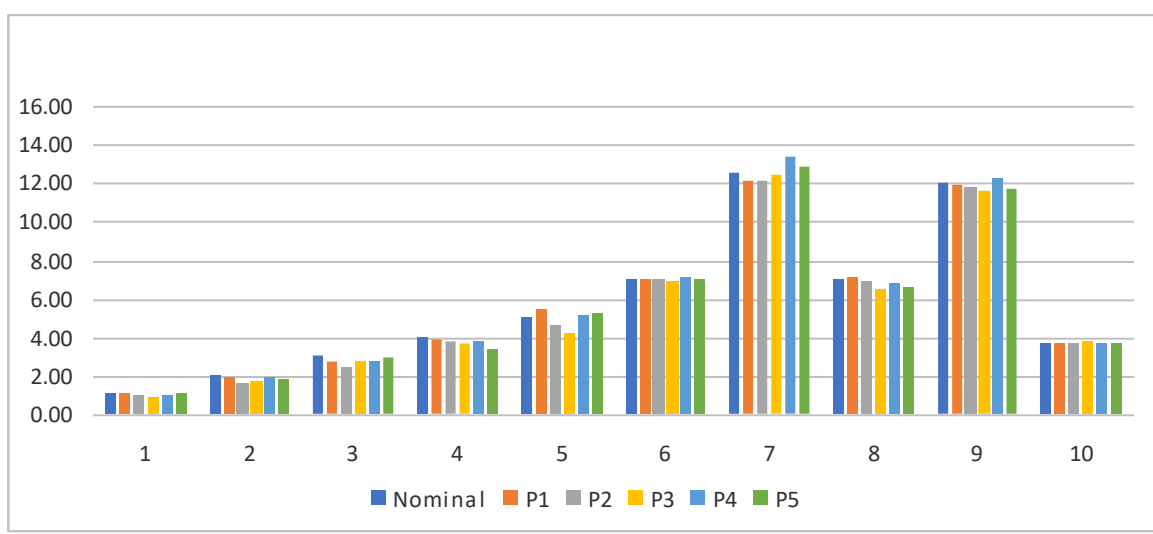

Figure 7: The variation of dimensional deviation for the five test models with the ten representative surfaces of the part in comparison with nominal dimension

From the picture presented in Fig. 7 we may conclude that for the external dimensions of the Part, such as surface 6 , the minimum deviation values are for the PLA material green and for the composite wood material too. The variation of dimensional discrepancy is presented in Fig. 7 for the ten surface types and five material types used for manufacturing.

We may infer that for the environmental constant temperature $23 \pm 1^{\circ} \mathrm{C}$ we may analyze the errors of shape. The main conclusion is about allocation of tolerance field that is done inside the range $\pm 0.2 \div 0.6 \mathrm{~mm}$ depending on the material type and the 3D printer type.

\section{Conclusions}

The main factors that influence the printing accuracy by using FDM process are: the computational accuracy of STL file, the orientation of 3D model inside the working room of the printer, the nozzle diameter specific for the material, the section step for model cutting, the overall 
dimensions of the model, the part complexity, the accuracy demanded for the details.

The accuracy of STL file influences the part accuracy. The poor quality of this file means big deviations from the CAD model, so misfit parts would be manufactured.

The model orientation inside the working room is important from the accuracy point of view, because the boarding elements will be more precisely than the elements made by construction during the process. We have to recommend the optimum part orientation, so that the surfaces with high accuracy would be made by board manufacturing.

The nozzle diameter for material extrusion influences the manufacturing accuracy by the thin value for the thread. The greater the diameter value, the bigger the length of material deposit section. Consequently, there are some limitations of manufacturing possibilities especially for the required precise dimensions.

The cutting step for the virtual model influences the manufacturing accuracy due to the step effect during the process. The bigger the step, the lower the accuracy even though the model has been very well designed. The step effect is more obviously when we have to manufacture the inclined surfaces along the horizontal plane.

The maximum overall dimensions of the part should be no greater than the working room dimensions of the printer including the final stroke for the extruder. If there are some dimensions outside the working room, it is recommended to obtain two parts, which will be assembled later.

Finally, the accuracy of the product will be lower by comparison to that of single part, but it could be improved, if some elements for relative positioning had been designed.
The part complexity regarding the small dimensions, lower than $0.2 \mathrm{~mm}$ inside the thread diameter for instance, will be lost. As we may infer, the most important effect will be the accuracy decreasing. The material technical properties are some important factor that influences the manufacturing accuracy, so we have used PLA because all the printers we have used do not have warmed working table $[1,2]$.

\section{Acknowledgement}

This work has been funded by University Politehnica of Bucharest, through the "Excellence Research Grants" Program UPB - GEX 2017. Identifier: UPB - GEX2017, Ctr. No.48/25.09.2017, ME14-17-05, ID 98.

\section{References}

[1] Petru Berce, Nicolae Balc, Cristian Caizar, Razvan Pacurar, Adrian Sever Radu, Sorin Bratean, Ioan Fodorean, Tehnologii de fabricaţie prin adăugare de material şi aplicaţiile lor, Editura Academiei Romane, Bucureşti, 2014.

[2] P. Berce, N. Balc, M. Ancau, S. Comsa, H. Caizar, H. Chezan, Fabricarea rapidă a prototipurilor, Editura Tehnică, Bucureşti, 2000.

[3] Mircea Mihai Popovici, Modelarea virtuală 3D în construcţia de maşini, Bucureşti, 2005.

[4] P. Precupeţu, C. Dale, Th. Nitulescu, Desen tehnic industrial pentru construcţii de maşini, Editura Tehnica, București, 1982.

[5] Aurel Ciocîrlea Vasilescu, Metrologie industriala, Cvasidocumentaţia Proser\&Printech, Bucureşti, 2005.

[6] www.makerbot.com/replicator 